\title{
IoT Based Smart Healthcare Services for Rural Unprivileged People in Bangladesh: Current Situation and Challenges ${ }^{\dagger}$
}

\author{
Mohammad Monirujjaman Khan \\ Department of Electrical and Computer Engineering, North South University, Bashundhara, Dhaka-1229; \\ monirujjaman.khan@northsouth.edu \\ * Correspondence: monirujjaman.khan@northsouth.edu; Tel.: +8801779006296 \\ † Presented at 1st International Electronic Conference on Applied Sciences, 10-30 November 2020; Available \\ online: https://asec2020.sciforum.net/.
}

Published: 10 November 2020

\begin{abstract}
Internet of Things (IoT) based smart health monitoring system is a new idea for Bangladesh. In Bangladesh almost 70 percent of people are living in rural areas. Instant access of proper healthcare service is very difficult for the rural people in Bangladesh. MBBS doctors and suitable healthcare-related facilities are not generally accessible in the rural part of Bangladesh. People in rural areas of our country suffer very much for getting proper healthcare services. IoT based smart healthcare service is very important in our country especially for rural areas. This paper introduces and analyzes the current situation and challenges of IoT based smart healthcare services for rural unprivileged people in Bangladesh. IoT based healthcare service provider companies of Bangladesh are introduced and their current status in this field have been identified and discussed. Mobile and web application based telemedicine services also have been introduced. Research shows that IoT based healthcare service provider companies are facing some challenges in this field which also have been introduced.
\end{abstract}

Keywords: Internet of Things (IoT); Smart Healthcare; Challenges; Rural Areas; Situation; Mobile Phone; Covid-19; Bangladesh

\section{Introduction}

Bangladesh is a very heavily populated country. At present the population of Bangladesh is more than 164.7 million. Presently, there are 593 government emergency hospitals, 467 association level hospitals, and 126 optional and tertiary levels medical hospitals in Bangladesh. Apart from this, 2983 private hospitals and 5220 private diagnostic centers are providing day and night healthcare services. In Bangladesh, there are only 6 hospitals for every 1 million people, which are not sufficient for a vast number of people. To strengthen the healthcare industry, a lot of research work is being carried out to explore new, accurate and efficient technology that can monitor patients in everyday life [1].

Information and communication technologies (ICTs) have great potential to address some of the challenges faced by both developed and developing countries in providing accessible, cost-effective, high-quality health care services. Modern information and communication technologies (ICTs), such as computers, the Internet, and cell phones, are revolutionizing how individuals communicate with each other, seek and exchange information, and enrich their lives. These technologies have great potential to help address contemporary global health problems. One of the blessings of ICT is Telemedicine which is playing a special role in providing emergency health services. Telemedicine is the use of information and communication technologies (ICT) for healthcare services [2].Telemedicine fundamentally means monitoring the health of the patient through the use of Proceedings 2020, 4, x; doi: FOR PEER REVIEW www.mdpi.com/journal/proceedings 
computers, mobiles and other technological applications. It refers to the provision of remote clinical services, via real-time two-way communication between the patient and the healthcare provider, using electronic audio and visual means [3-4].

Healthcare monitoring systems in Hospitals and many other healthcare centers have experienced considerable growth and portable healthcare monitoring systems with emerging technologies are becoming of immense concern in many countries. For the past decade, Information and Communication Technology (ICT) has been playing a significant role in the development of the health care sector in Bangladesh. The beginning of Internet of Things (IoT) technologies facilitates the progress of healthcare monitoring systems which facilitates the progress of healthcare from face-toface consulting to telemedicine [5]. Internet of Things (IoT) based smart healthcare system is a real time patient monitoring system in which a patient can be monitored remotely. In the present world, IoT is changing the infrastructure of technologies. Health monitoring systems are one of the most notable applications of IoT. Many types of designs and patterns have already been implemented to monitor a patient's health condition through IoT [6].

The Internet of Things (IoT) based healthcare system interconnects various medical resources using IoT and distributed databases to provide effective and smart healthcare service to the elderly and patients with chronic illness. IoT based smart healthcare is a great solution in rural areas of Bangladesh where it is not possible to get a MBBS doctor immediately. People in rural areas of Bangladesh suffer a lot for getting proper healthcare services [7].

The Internet of Things (IoT) based healthcare system is a technology that has made a major impact on the healthcare industry but there are many challenges and open issues exist that need to be addressed and find solutions [8]. This paper focuses on the introduction and analysis of the current situation and challenges of IoT based smart healthcare services for rural unprivileged people in Bangladesh.

\section{IoT Based Smart Healthcare System}

Figure 1 shows the architecture of IoT based smart healthcare systems.

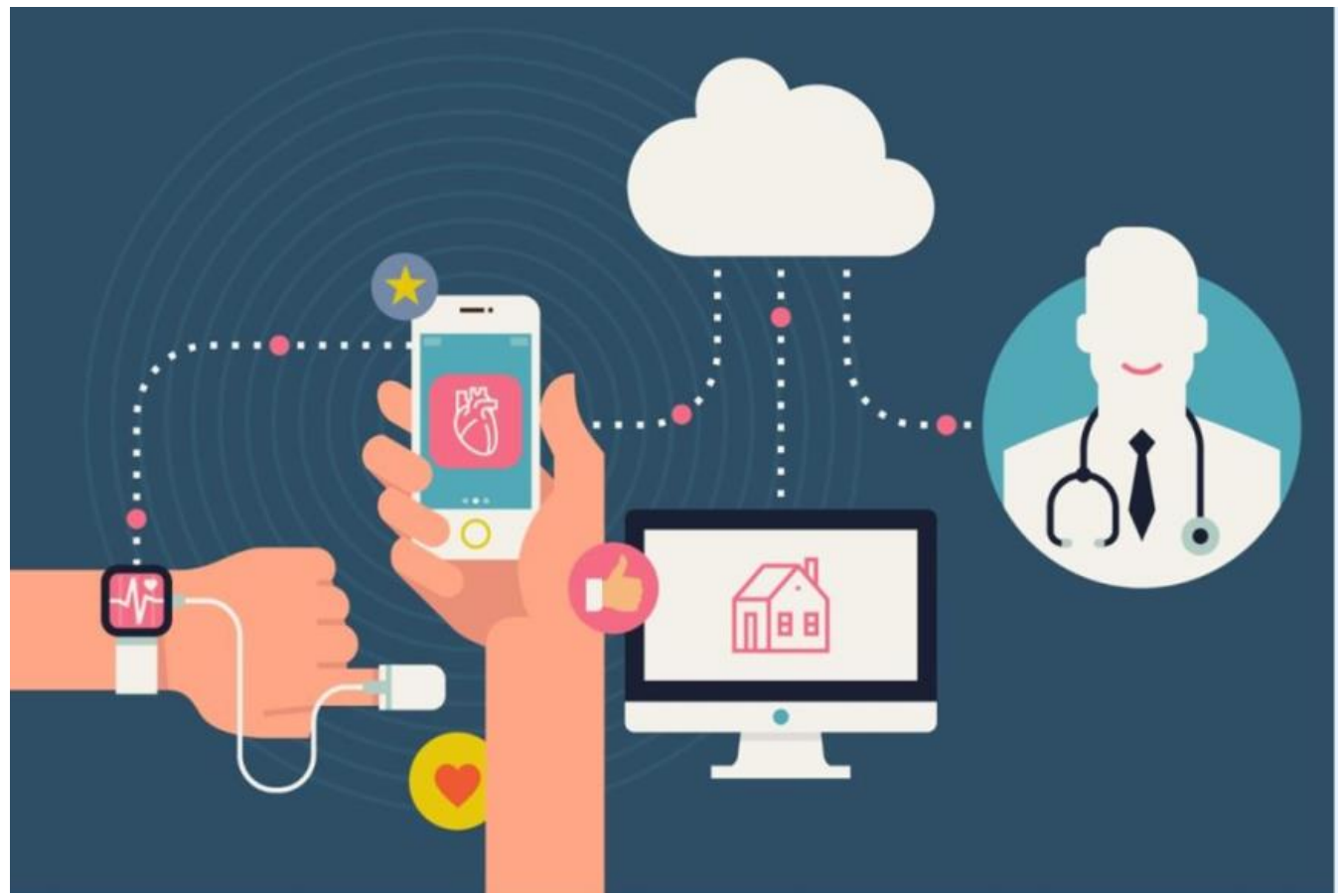

Figure 1. Architecture of IoT based healthcare systems.

The IoT based smart healthcare service for rural people in Bangladesh is basically through the use of smart medical devices, mobile phones, mobile and web applications and computers. With the help of IoT based healthcare services, patient's health is monitored remotely by the experienced MBBS 
doctors and prescription is provided to patients online; see Figure 1. Figure 2 shows smart IoT based medical device. In Figure 3 mobile application for smart healthcare services is demonstrated. Using smart medical devices and mobile application patients physiological data is measured and sent to MBBS doctors online.

Recently, some companies in Bangladesh are providing telemedicine healthcare services. Few of them are only focusing on web and mobile applications based online telemedicine services. Few companies are providing IoT based telemedicine healthcare services. In the next section introduction, operation, current situation and challenges of these types of companies in this field are provided and discussed.

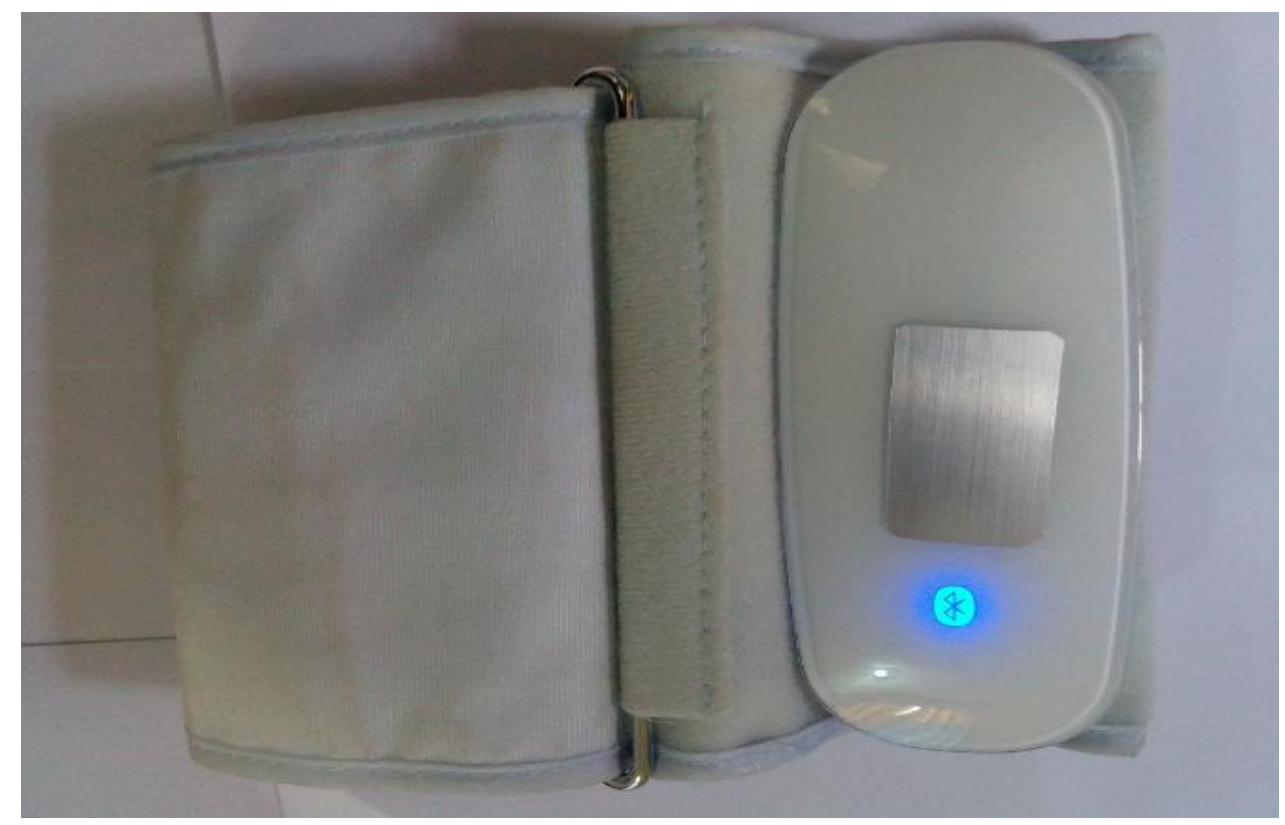

Figure 2. Smart IoT based medical devices.
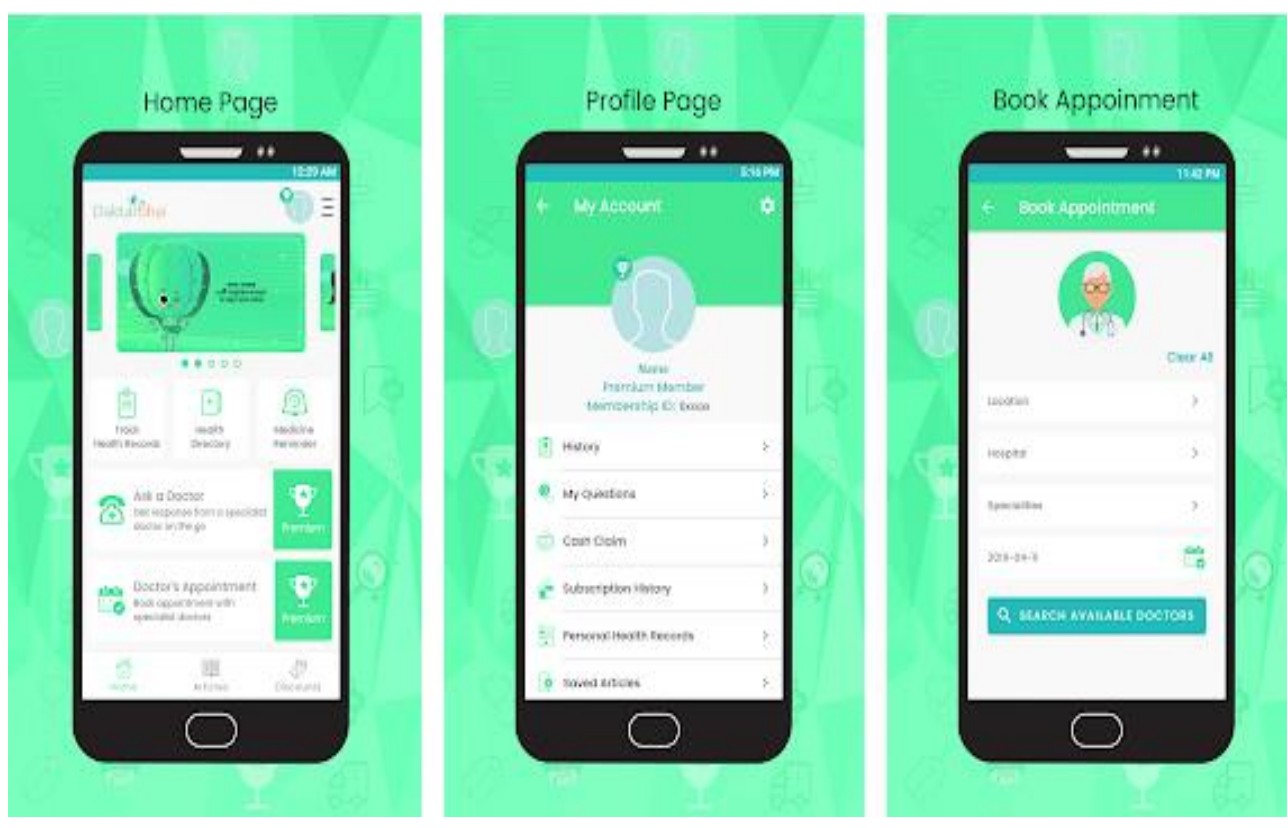

Figure 3. Mobile application for smart healthcare services.

\section{Current Situation and Challenges}

As mentioned earlier some companies in Bangladesh are currently providing online telemedicine healthcare services. Among them Jeeon, CMED, e-Hospital, Dhaka University 
Telemedicine Services, Bachao, Tonic, Sebaghar, Pulse and Daktarbhai are playing one of the most important roles in Bangladesh. Jeeon, CMED, e-Hospital and Dhaka University Telemedicine Services are providing IoT based smart healthcare services for the rural people [9-12]. In addition, CMED is also providing preventive health care services through the use of IoT cloud based healthcare systems. Figure 4 shows a real life rural medical centre for IoT based smart telemedicine healthcare services. In Figure 4 rural patients and medical assistant are noticed. Except other healthcare companies, Jeeon has stopped their services of IoT based Telemedicine healthcare services to the rural people. They have faced different challenges in this field during their operation of healthcare services. However, due to Covid-19, the demand of telemedicine healthcare services have increased. Telemedicine is getting more mainstream during the covid-19 pandemic time [13].

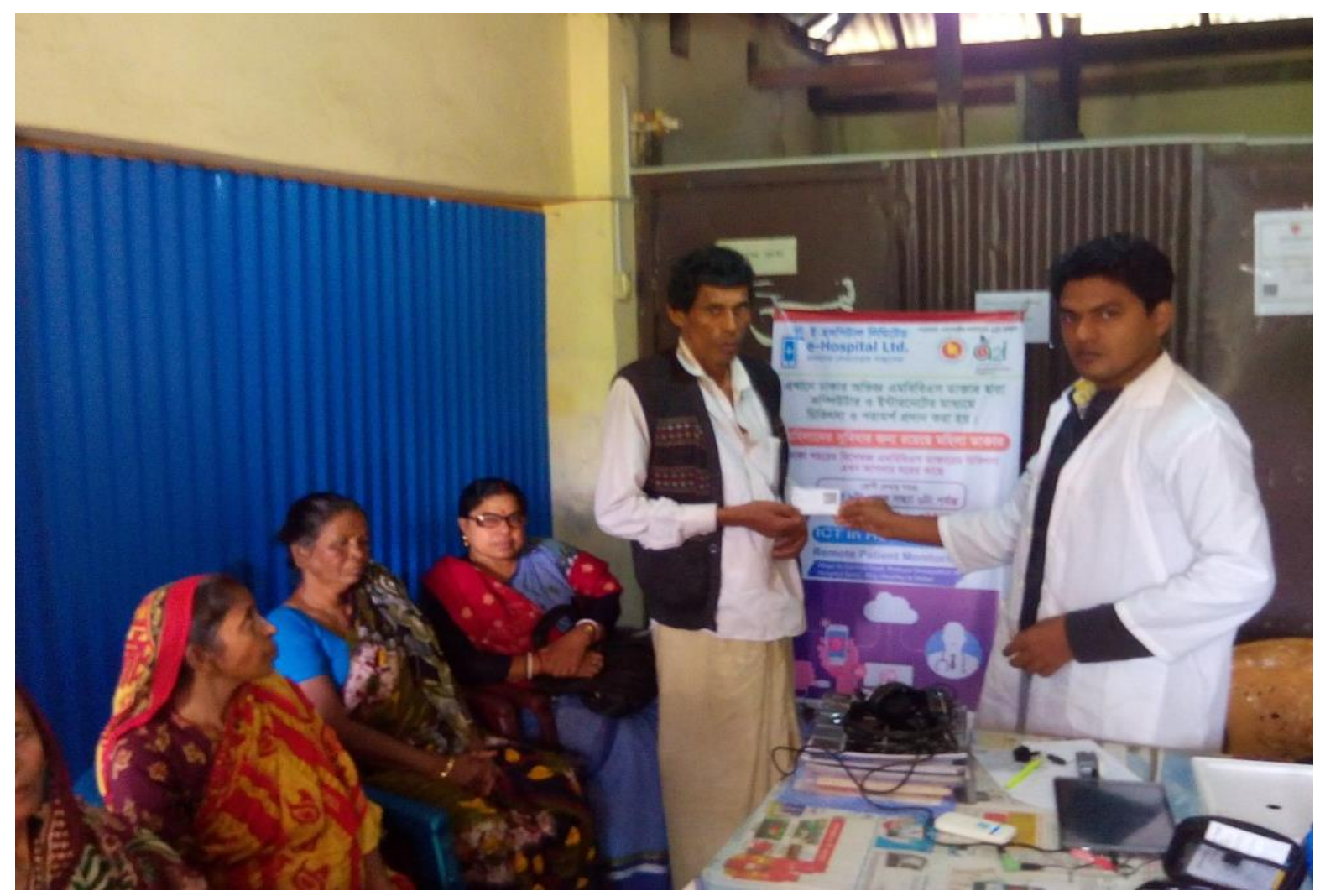

Figure 4. Rural medical centre for smart IoT based healthcare services [11].

Some companies are operating telemedicine services in Bangladesh as we discussed earlier. IoT based smart telemedicine healthcare services are a new healthcare solution in Bangladesh. Although telemedicine healthcare services are becoming famous nowadays due to Covid-19, this sector still faces many challenges. The main challenges are provided below:

- Limitation of technical resources

- Patients acceptance

- Lack of interest in adopting new technology of people

- Lack of proper marketing of this system

- Trust issues of patients

- Awareness of people especially of rural people

- Lack of operation fund of the startup company

- Lack of expert team to run the startup company

- Staffs motivation of not to work in rural areas 
Due to these above mentioned challenges some companies are still struggling to be successful in this field. Dhaka Medical Telemedicine Services that provides IoT based telemedicine healthcare services have merged with other companies to overcome some of the challenges as mentioned above. They are now working with Bangladesh Rural Advancement Committee (BRAC). Although, companies are facing some challenges now to provide and continue IoT based telemedicine services for rural people in Bangladesh, a proper solution is needed to overcome these challenges. In future IoT based smart healthcare services will be a blessing not only for the rural people but also for the people in the whole world. Due to lack of page and space limits more description are not provided here. However, author of this paper is currently writing a review article on this topic with more detailed discussions and findings which will be submitted in the Applied Science Journal of MDPI.

\section{Conclusion}

Investigation of IoT based smart healthcare services for rural unprivileged people in Bangladesh is provided in this paper. Companies that provide IoT based Telemedicine healthcare services for rural unprivileged people in Bangladesh are discussed. Mobile and web based Telemedicine companies are also mentioned in the paper. The current situation and challenges of IoT based smart Telemedicine healthcare services from the perspective of Bangladesh have been analyzed. With the help of IoT based smart telemedicine healthcare services rural people are getting medical facilities staying at their own location. They do not need to travel far distances to get the medical consultation of MBBS doctors and basic medical tests. This system is helping rural people now to a great extent for the medical treatment, consultation and medical testing purposes. It saves time, cost and travels of rural people. Health of remote patients are monitored and treatment plan is provided from the city with the help of this system to this service. Companies who are operating telemedicine services in Bangladesh are playing a very important role in digitizing our medical system. In covid-19 pandemic, they are helping patients providing online medical services therefore patients are getting the healthcare services staying at their home. Due to the high-speed internet and good telecommunication network, it has been possible to provide e-healthcare in isolated areas where modern medical facilities are absent. Digital healthcare is a new idea and most of the people in our country are living in villages. We need to create awareness of these people about health. Therefore, private companies also need support from the Government. Healthcare is a big area and it is very important for people. Although startup companies in this field are facing many challenges to provide IoT based healthcare service in Bangladesh, we need to find a proper solution for this issue. This paper focused on the situation and challenges for the implementation of this system in our country that will help to develop the application of this system further. This system will be a blessing in future for the people of the whole world.

Author Contributions: Author of this paper has done the required study and research to write the paper himself. He has written the paper alone.

Funding: This research received no external funding.

Acknowledgments: Author would like to thank IoT based smart telemedicine service provider companies of Bangladesh for sharing their experiences with the author. Author also would like to thank the staff of e-Hospital Ltd. The author of this paper is the founder and managing director of e-Hospital Ltd. that provides IoT based smart telemedicine healthcare service for the unprivileged remote rural people of Bangladesh. Author also would like to thank a2i, the project of the Prime Minister's Office of Bangladesh for providing the fund to develop the remote patient monitoring system [14].

Conflicts of Interest: The authors declare no conflict of interest.

\section{References}

1. Mostafa, R.;Rahman, R.; Deployments to Provide E-Healthcare in Bangladesh: Urban and Rural Perspectives. 12th IEEE International Conference on e-Health Networking Applications and Service 2010.

2. e-Health. Available online: https://www.who.int/ehealth/en/ (25 October 2020) 
3. What is Telemedicine. Available online: https://www.news-medical.net/health/What-is-Telemedicine.aspx (accessed on 1 September 2020).

4. e-Health. Available online: https://innovatemedtec.com/digital-health/ehealth (25 October 2020).

5. Broderick, M., \& Smaltz, D.H. (2003). E-Health Defined. HIMSS E-Health SIG White Paper. Retrieved October 11, 2009 from www.himss.org/content/files/ ehealth_whitepaper.pdf

6. Islam, M.M., Rahman, A \& Islam, M.R. Development of Smart Health Monitoring System in IoT, Environment. SN COMPUT.SCI.1, 185 (2020).

7. Rahaman, A., Islam, M.M., Islam, M.R., Sadi, M.S., Nooruddin, S. (2019). Developing IoT based smart health monitoring systems: A review. Revue d'Intelligence Artificielle, Vol. 33, No. 6, pp. 435-440. https://doi.org/10.18280/ria.330605

8. Birje, M.N., Hanji, S.S. Internet of things based distributed healthcare systems: a review. J. of Data, Inf. and Manag. 2, 149-165 (2020). https://doi.org/10.1007/s42488-020-00027-x

9. Jeeon. Available Online: https://www.jeeon.co/home/ (accessed on 10 May 2020).

10. CMED. Available Online: https://cmed.com.bd/\#news (accessed on 10 May 2020).

11. e-Hospital Ltd. Available Online: https://www.startany.com/e-hospital-ltd (accessed on 10 May 2020).

12. Telemedicine. Available Online: https://bmpt.du.ac.bd/telemedicine/ (accessed on 10 May 2020).

13. COVID-19 makes telemedicine more valuable; hub at Dartmouth-Hitchcock is ramping up. Available online: https://www.concordmonitor.com/telemedicine-covid-coronavirus-nh-33351977 (accessed on 21 March 2020).

14. Remote Patient Monitoring System. Available online: https://a2i.gov.bd/innovation-fund/(accessed on 10 May 2020).

Publisher's Note: MDPI stays neutral with regard to jurisdictional claims in published maps and institutional affiliations.

(C) 2020 by the authors. Submitted for possible open access publication under the terms and conditions of the Creative Commons Attribution (CC BY) license (http://creativecommons.org/licenses/by/4.0/). 